\title{
Socially Responsible Research as a Critical Path to Foster Rational and Ethical Analyses in Biased Public Debates: The Example of a Renewable Energy
}

\author{
Sébastien Bayon ${ }^{1}$, Jean-Claude André ${ }^{1,2}$ \\ ${ }^{1}$ Laboratoire Réactions et Génie des Procédés - Unité Mixte de Recherche CNRS - Centre Nationale de la Recherche Scientifique / Ecole \\ Nationale Supérieure des Industries Chimiques, Universite de Lorraine, Nancy, France \\ ${ }^{2}$ INSIS - Institut des Sciences de l'Ingénierie et des Systèmes / CNRS - Centre Nationale de la Recherche Scientifique, Paris, France
}

\section{Email address:}

sebastien.bayon.2602@gmail.com (Sébastien B.), jean-claude.andre@univ-lorraine.fr (Jean-Claude A.)

\section{To cite this article:}

Sébastien Bayon, Jean-Claude André. Socially Responsible Research as a Critical Path to Foster Rational and Ethical Analyses in Biased Public Debates: The Example of a Renewable Energy. Science Journal of Energy Engineering. Vol. 5, No. 6, 2017, pp. 158-168. doi: $10.11648 /$ j.sjee.20170506.15

Received: October 31, 2016; Accepted: December 30, 2016; Published: January 8, 2018

\begin{abstract}
The development of new technologies crossed more and more by means of inquiries to the public. At the same time, the researchers should be more and more led to explore socially responsible research principles to take into account aspects like supplies, risks and social perception of the systems which they allow. A certain number of data was calculated from Life Cycles Analysis, allowing confrontations in relation to citizen opinions expressed in the case of the Aeolian energy system. The work linked with this paper agrees with some published results, but also highlights a trend of certain scientists coming from the "hard" sciences to assert opinions located outside the techno-economic reality. This result does not meet for the general population which agrees better to not know. This unforeseen situation asks then the important question of links to be developed between science, technology and society.
\end{abstract}

Keywords: Public Debate, Precautionary Principle, Uncertain Risks, Social Perception, Expertise

\section{Introduction}

During decades, in the working of scientific and technical knowledge, the public was principally defined by negative aspects, by a defect of aptitude for the access to knowledge. Then, communication was a rather secondary activity for the owners of knowledge and policies. It was at best a necessary evil in a one-way relationship, from the top to downwards (separation between technical knowledge and public opinion). The skills of experts and decision makers on subjects as technical practicability, cost control, security, risks for the Human and the environment, etc. is normally necessary. ([46]; [47]). Besides, the gap between elites likely to manipulate behaviors of the citizens, to move them away from the heart of debate and make them acceptable, or even desirable once decided for themselves is not bearable any more. This situation, which will be discussed, leads to take into account the initial perception of the Society in the scientific and technological development.

In this frame, one of the authors ([4]) has proposed of charter of Socially Responsible Research (SRR) which comes back into this vision. If research units of INSIS (one of ten CNRS institutes, engaged in researches in engineering sciences) were consulted and claimed their interest for this proposal, as of day, any involves in process, for different reasons explained below. To try to persuade the scientific and technical community of the interest of this ethical and responsible principle, the authors chose to show how they can get involved in SRR:

1-By illustrating the purpose on the basis of socioeconomic methods applied to the case of researches on the Aeolian (particularly by the optimized choice of materials) ([7]);

2- By trying humbly to show how research can lean on the perception of the technical progress allowed by engineering sciences.

The object of this article is, after recalls on relationships 
between science, technologies and society, to introduce the results of a survey addressed to the mainstream on their perception and knowledge of the Aeolian technology. If one can highlight heavy societal trends concerning the Renewable Energy Sources (RES) which are the object of obvious forms of desirability, one has to admit certain problems of perception, on behalf of a hard-intellectualized public, in this form of production of now well enough known renewable energy. This unforeseen result underlines a relational difficulty which could restrict the opening vision of the researchers eager to share their works led to the "profit" of the Society; in any case, to understand better the processes of perception of a public, certainly more educated than in the past, but who, perhaps, is not led to take the necessary time to try to deepen the problems of technological development led in favor (or not) of the Society.

\section{The Relation of the Public to Science}

The acceleration of technical progress and innovation in all its forms is a silent revolution which upsets the State, the citizen, the employee, the hierarchical system in the company, the company itself which is relinquishing its role of vertical integrator for that of modular production, etc. ([36]). Constraints linked to new temporalities are imposed on researchers and on companies committed to enhance their performance (from individual to global) with a view to achieve the improved competitiveness vital to survival in the present value system based on only one variable of instantaneous interest: very short-term financial profit. This context is modifying the sense given to the fundamental concept of work and production, even for knowledge, but has shaken rigid frameworks, inertial habits; it is thus creating sometimes creative disorder and also concern.

\subsection{The Risk Society}

According to Beck ([8]), we are shifting from an industrial society whose central objective was a certain form of wealth distribution to a society centred on another form of distribution, that of risks. Thus, on this basis, risk becomes a constitutive element of society. It is new in nature, leading to the redefinition of social and political dynamics based on a new distribution of risks and the development of individualisation. Then, "science is becoming increasingly necessary but less and less sufficient in the development of a socially established definition of the truth".

Giddens ([31]) presents a slightly different vision; he portrays modernity where comfort and anxiety, safety and hazards, and softening and hardening in the management of social conflicts ambivalently live side by side. He distinguishes three discontinuities between modern and traditional social institutions: the speed of change, the scope of the change and the intrinsic nature of modern institutions. Others can be evoked, like those linked to the irreversibility of the transformations, etc.

Generally speaking, environmental research explores indirectly the evolution of context which has known unprecedented change. The time and space dissociation, such as those of relocation of social systems and reflexive (re)organization of social relations, contribute to the dynamic and the modernity and result in a suspect reality and uneasiness. Research institutes involved in innovation are confronted with maintaining trust between those subjected to the risks and those producing them by relying on "success stories" that highlight measurable improvements in working and living conditions. These elements illustrate the fact that know-how and knowledge of environmental risk prevention are only at the heart of our "world" when carried by a social existence: it is not scientific knowledge itself that must control the innovation process, but the knowledge and know how received in the specific forms of appropriation and valuation found within the social debate.

\subsection{Socially Responsible Research (SRR)}

It is necessary, in an obvious way, to be responsible. It does not mean that creativity and innovation must be completely tied down, because it will always be necessary to struggle against all conservatism and to respect the pressures of the financing agencies and disciplinary evaluation ([40]). INSIS has proposed a charter of Socially Responsible Research (SRR) ([4]) to avoid staying in a tropism towards the "certainty" which could make the researchers to sacrifice reality to an unacceptable abstraction (modeling often hides ignorance ([12])). Researches linked to the development of technology are elements which indeed begin being discussed, but that require going out of an only "scientist" discourse to invest also aspects of subjective perception ([17]). If some people wish a careful attitude by taking into account the social dimensions of the technological innovations allowed by Science, before waiting to be lit by a public agitation, one has to admit that techno-scientific development transforms, in an insidious way, the sense of what is human (increase of ease, but credible risks for health, environment, various estrangement). Then, it is desired to expand disciplines and behaviors of the scientists, so as to fit in with their research activities, the awareness of their social responsibilities. The foundations of SRR, elements of the charters of sustainable development, are the following:

- The SRR covers the social and environmental matters in the activity of a research team;

- The SRR is not and should not be separated from the action strategy of the research laboratory as it is about integrating social and environmental concerns into the activities;

- The SRR is a voluntary concept;

- An important aspect of the SRR is the way laboratories interact with those directly committed, both internally and externally (employees, clients, close environment, tutelage, decision makers, partners, stakeholders, etc.).

A list, non-exhaustive at this stage, is presented below:

- Traceability: this investment is essential to strengthen the trust between partners, in particular with companies (quality standards, best practices, etc.);

- Responsibility: respect (a minimum) of the regulations 
relative to research operations: protection of researchers and the environment;

- Respect of the laws governing ethics (human experimentation, animal experimentation, information technology and liberties, etc.);

- Originality/novelty: reflection on the launch of research operations whose result cannot be foreseen by knowledge of the "previous art"; this means a better creation of effectively new knowledge via scientific development or exploitation of interdisciplinary projects. There must be permanent questioning of its practices;

- Conscious analysis of the use of the results of the research for Society (this means a useful but difficult reflection because of uses of the same concept for different ends);

- In-depth reflection on the uses of the artefacts in Society: use and associated perturbations, recycling, risks of irreversibility, sustainable development, short, medium and long term effects on the environment; relationships with humans: risks, social justice and even-handedness, development of the human personality, etc.;

- Periodic return to and review of the different items according to the advances in scientific knowledge and their effects;

- Management alert mission if new at-risk situations appear to be emerging.

\subsection{The Public Debate}

It is the general weakening of traditional pillars of the public decision, the legitimacy of political presentation and the authority of science, which provoked, in answer, the actual participative turn, driving to the official creation in France of public debates. In this context, a decision could, in a bit amazing way, become legal, not by the virtuousness of the unction of universal suffrage or science, but because concerned persons would have been linked there... Then, the participation in a public debate could constitute a tool of social engineering of the approval of the public as a whole! The law L.95-101 of February 2nd, 1995, relating to the protection of environment, called Barnier's Law, introduced in France the procedure of public debate, one of numerous decision-making steps before the achievement of a project. It considers the association and the participation of the public in "the elaboration of the plans of development or equipment having an important impact on environment or on town and country planning".

Public debate concerns opportunity, characteristics and objectives of a plan, implying potentially research aspects ([45]). It must allow:

- To inform the public on opportunity, characteristics and objectives of the plan;

- To secure the broadest possible expression of the public with the aid of different support;

- To light the master of work by new elements of evaluations.

Since several years, France hired two important debates which can have consequences to the future of our Country: the debate on nanotechnologies, hired between 2009 and 2010 and more newly that one called CIGEO for the underground stocking of nuclear waste (2013-2014).

Some criteria have to be taken into consideration: inform honestly (not to format the public), communicate also honestly and have talks (in a horizontal way). "The respect for others allows going out of the relationships to others founded on domination. It institutes, in effect, an egalitarian relationship, not fusional, not hierarchic, borrows of a certain sympathy / empathy" ([37]). Indeed, "any live together obliges in a minimum of understanding on the good, the righteous man, the reasonable, or, in everything least, on certain ways commonly accepted or rightfully imposed to insert contradictory interpretations into these regulating values of the flux of social reports" ([25]. [26]). What they determine in a general way, with an educated population, with a social context which profoundly mutated since the Thirty Glorious Years, it is that the old bipolar schema between the experts and the citizen disappears. It gives up the place in a pluralist, hard heterogeneous schema, hired in not prioritized relations, in which numerous groups of interests interfere to confront one another or sometimes, on a particular aspect, collaborate.

However, participation concerns only citizens' small minority, in the best of cases. It is very unequal socially; those who get involved most resolutely tend to become in their tower of the professionals of policy, direct public debate or via mass media, and of expertise, "professionals" in the service of social movements, NGOs or Community associations, but of really experts, knowledge of which sometimes resembles more that of the specialists of communication, politicians, etc. whom they question, that in that of their members (when it exists). Finally, that becomes the neutrality searched in debates if a part of these new "professionals", constituted by irreducible opponents in a project, refuses to participate in a pooling of positions in relation to a debate.

Applied to these two cases, the orientation of question focused on benefits / risks, without other domains being the object of the attention of the participants, all haunted, rightfully by risks for his health is questioned. This proximity favors potentially extremisms and clashes of a public forced to get involved in the dichotomous management of a purely administrative report ([9]). Pesqueux ([44]) considers that they are in a weaving established between an objective, verifiable scientifically discourse, the ethos of responsibility and the pathos of fairness: "identification and neutralization of all thinkable environmental risks, approach objectifies of each of them (allowing considering certain as being negligible) and formulation of rhetoric of not risk". They cannot consider that in the short duration of a debate (four months), the public is rather going to be interested in what makes sense, without having the means of deepened investigations, leaving this field of technical expertise to the possessors of powers with possibility of orientating debate and why not decisions which are going to follow from it. "The technicization of language 
leads to word of serfdom and when word is of serfdom, everything is of serfdom" ([22]). Close to these sceptics for a debate with whom it is possible to exchange, are irreducible opponents for whom "to make participate, it is to make accept" ([17]): Technophobes in essence, rejecting technological progress as a whole with sometimes a vision of totalitarian Utopia, these opponents, in weak number, but particularly efficient to constrain public debate, prevented, in these two public debates of national importance, that a vision partly shared between stakeholders is built.

These elements allow to identify dissonances and consonances, possible alliances, disjunctions; they illustrate large heterogeneities in the positions of the different actors concerned by a project, their knowledge and know-how to participate in the debate, driving to finally irreconcilable proposals at least because trust is not anymore and restored by debates. This de facto situation goes of protest towards the techno-liberal modernity, up to certain forms of manipulation or propaganda translated at the end by a bipolarization, of disjunctions which go contrary to the mind of debate, the whole in the presence of dumb audience, to large number. Numerous comments exploring the "failure" of public consultations and show that problem are linked to an analysis of risks and vulnerabilities, in the mastering of ethical elements which connote the object of debate. And, as it was specified, in the field of uncertain risks they are led to explore the precautionary principle. "Circumspection indicates the attitude one asks for which somebody who they say to that beyond the risk which it controls and what he can measure, he/she must take into account a risk which he/she is not going to know yet but who is likely to show himself, in future, in new state of science" ([24]). Each can, envisage the social impact of the application of a concept by wondering about the building of phenomena and their consequences. Besides, while thinking of novelty from a located filiation it is possible:

- To make believe in the Society that it is just about a purely technical object;

- Of focus debate on the reductionist schema benefits / risks;

- To perform an ideological communication to say that the technology, consequence of concept, is resolution;

- To forget the emotional and spiritual load concept of which is bearing ...

\section{The Way Forward - An Example}

Renewable energy sources constitute an emergent form of production of electricity which makes the object of passionate debates. Our goal was to estimate the interest of the development of technologies of this nature. We were interested in the case of the Aeolian technology which constitutes a bearing area, that concerns nearly or from a distance, the whole population. The deployment of renewable energy sources is more displayed over the territory than traditional concentrated production. There is therefore a true social dimension to be taken into consideration, it is all object of this paper for which we proposed a survey. The cultural modes of production and linked up with the activities of the engineer are not approached; however, the return to new forms of use of energy is likely to change modes of thought and action in the processes of transformation of matter and energy and could therefore impact researches in engineering sciences. This subject was nevertheless considered as noticing from a specific activity that it would be necessary to lead in another frame.

\subsection{The Already Published Opinion Inquiries}

The results of several inquiries performed newly are introduced below:

- IPSOS Public Affairs ([35]) "Perception of wind force in Walloon area of Belgium".

According to this opinion poll, $86 \%$ of the concerned persons are in favor to the development of the Aeolian technology as a RES; risks for populations and environment are considered as not very important. An interesting question in the inquiry concerns the importance of familiarization (information, presence, etc.) in the positive perception of this RES. Nevertheless, a majority of the polling however consider not have enough information as: the production of electricity, the financial benefits, etc.

- Institute of opinion polls Louis Harris ([34]) "Opinion of the Frenchmen on wind force". Opinion would be very favorable to the development of this renewable energy ( $91 \%$ ) while considering (38\%) that it is likely to disfigure the landscape.

- French Commissariat Général au Développement Durable (2009) "The social acceptability of the Aeolian: riverians ready to pay to keep their Aeolian - Inquiry into four French Aeolian sites". This study accomplished for the French Ministry in charge of ecology and energy puts in an obvious place the same trends: strong support of the development of RES of this type, even if visual or acoustical nuisance are signaled.

\subsection{The Inquiry}

The study targets at the energy balance of this form of RES. The answer is important in the decision of new Aeolian plans allowing, appreciating perceptible energy winnings and the agreement of populations on the price to be paid for these deployments. It allows examining research topics to develop. The inquiry led over two months is significantly different (in positive and in negative) of three works summed up above by the following elements:

- Cohort is principally constituted of "hard" intellectualized persons (students, teachers, University staff, researchers) who can have a point of view scientifically more supported on a technological subject; an Internet link by personal relationships allowed to attain more than 1000 persons (with about 600 answers) without cohort being defined and be representative of the French population. Biases are 
therefore real.

- The target was concentrate on a perception of the cost of energy of Aeolian installations, question which had not been approached in previous opinion polls. So two questions, "infiltrated" in the inquiry specifically concern this aspect through the following questions:

- "According to you, what is the quantity of energy produced by the Aeolian plant which will have been used for its realization, its establishment, its maintenance and dismantling?"

- "Up to what additional cost are you ready to pay to augment the part of the renewable energy sources of Aeolian plant in French electricity network?"

The accomplished inquiry exploits modes of question led by professional interviewers, these two questions having been introduced in the text in a bit surreptitious way so that the attention of the polling is not focalized on these two central questions for this work.

\section{Perception of the Renewable Energy Sources in the French Public Debate}

\subsection{The Raw Results of the Inquiry}

We initially offered 25 questions to students of French "Grandes Ecoles of Engineers" of Lorraine. University staff members, researchers, $\mathrm{PhD}$ students, etc.) as connected persons also agreed to answer this questionnaire. This allowed us to establish a sampling $(n=593)$ wich is not representative of the French population. The bulk of the polling is familiar with science and technology, what should certainly accentuate the rocking of answers in comparison with national studies. It is in the comparison of results and the crossroads of this information that domiciles the interest of this study. To be able to compile answers, we accomplished the questionnaire through a "Google Documents" form.

According to the way they are formulated, questions can cause at the investigating of effects and reactions linked to phenomena of psychological order or psycho-sociological. These are mechanisms of defense of subject. Every individual will have tendency to defend, even completely subconsciously, a certain picture of himself, or a certain integrity-unit of his person facing this calling into question that is fact to confront a questionnaire. According to Giezendanner, ([32]), the trend to acquiescence is a systematic bias of answer amplified by a tendentious wording, they acquire then answers completely suggested by question. For a formulation of this type: "Must they insert sure techniques avoiding the exhibition of the persons or environment?" Yes - Not, waited / desired answer by the interviewer appears rather apparently. To frustrate this tendency, they would have been able:

- To reduce numbers / avoids closed questions of binary type (Yes / Not, Truths / Falsehood, etc.), to reverse from time to time, when they solicit the personal opinion of an individual.
- Have recourse to the principle of alternation by varying the wording of questions so that answer is favorable or disadvantageous to the same opinion.

- Formulate questions positively / negatively.

- Alternate positive and negative proposals in a battery of scales.

- Alternate favorable and enunciated disadvantageous wordings of the questionnaire.

- To reduce the number of the questions of type «You Agree with», «You suppose that».

- Ask twice the same question, by turning question, that is to say make two formulations compensated in suite.

We therefore tried to take into account these comments in the present inquiry. Such acquired results are gathered in faces and following tables and figures:

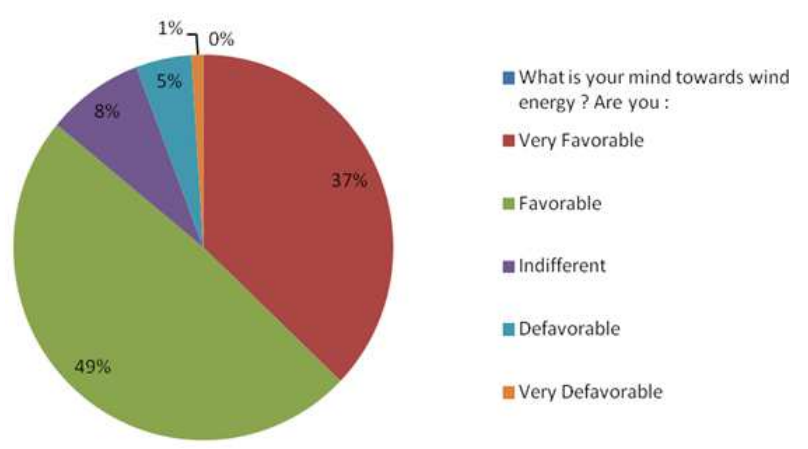

Figure 1. What is your mind towards wind energy? Are you.

Table 1. Do you have wind turbines in your neighborhood?

\begin{tabular}{ll}
\hline Yes & $22 \%$ \\
No & $78 \%$ \\
\hline
\end{tabular}

Table 2. In case there would be wind turbines in your neighborhood, are you favorable to their dismantling to return to a previous state?

\begin{tabular}{ll}
\hline Yes & $7 \%$ \\
No & $42 \%$ \\
Do not know & $15 \%$ \\
Not concerned & $36 \%$ \\
\hline
\end{tabular}

Table 3. If you were confronted with it, would you support a project of installation of wind turbines in your neighborhood?

\begin{tabular}{ll}
\hline Yes & $57 \%$ \\
No & $20 \%$ \\
Do not know & $23 \%$ \\
\hline
\end{tabular}

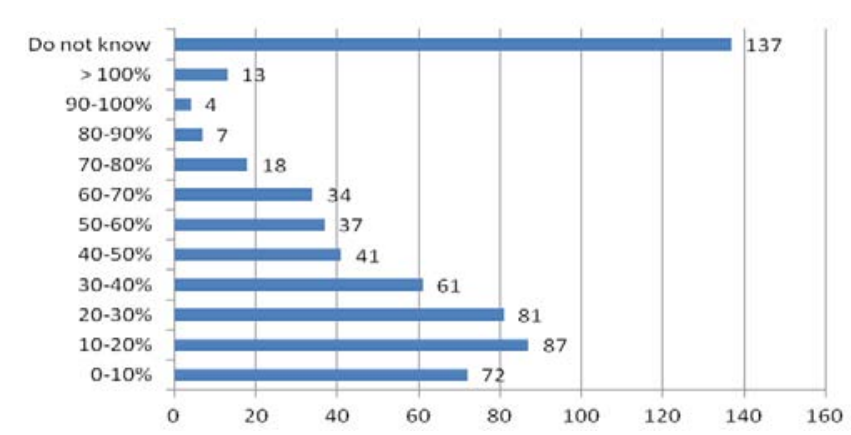

Figure 2. According to you, what is the quantity of energy produced by a wind turbine which has been used for its construction, its installation, its maintenance and its dismantling? 
Table 4. The average cost of the $\mathrm{kWh}$ in France is about $0.12 € / \mathrm{kWh}$ (basic rate), do you think the increase in renewable energy sources in the French electric mix will increase your electricity bill?

\begin{tabular}{ll}
\hline Yes & $54 \%$ \\
No & $32 \%$ \\
Do not know & $13 \%$ \\
\hline
\end{tabular}

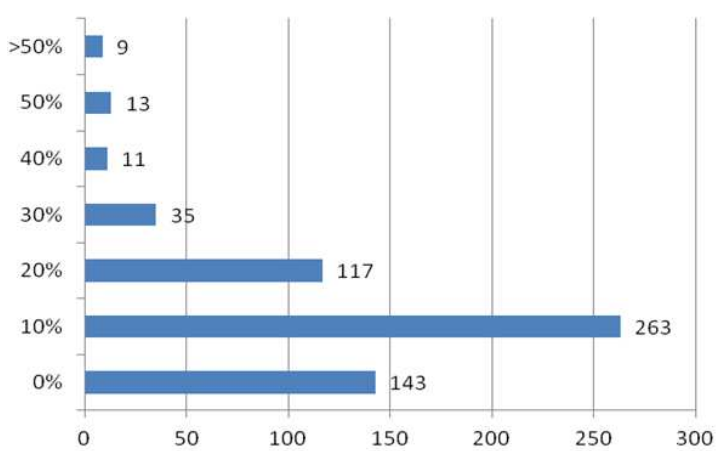

Figure 3. If yes, until which additional cost are you ready to pay to increase the part of wind energy in the French grid mix?

Table 5. Among the following proposals, which one can enter into consideration in the choice of the development of the wind energy? What criterion seems to be the most important for you?

\begin{tabular}{ll}
\hline Energy independence & $30 \%$ \\
Landscape preservation & $10 \%$ \\
Greenhouse gas emission reductions & $60 \%$ \\
\hline
\end{tabular}

Table 6. Second criterion you will take into account?

\begin{tabular}{ll}
\hline Energy independence & $55 \%$ \\
Landscape preservation & $17 \%$ \\
Greenhouse gas emission reductions & $28 \%$ \\
\hline
\end{tabular}

Table 7. Do you think you the installation of wind turbines in your town will give it a more modern image?

\begin{tabular}{ll}
\hline Completely agree & $15 \%$ \\
Rather agree & $44 \%$ \\
Rather not agree & $17 \%$ \\
Not agree at all & $11 \%$ \\
Do not know & $13 \%$ \\
\hline
\end{tabular}

Table 8. In the same perspective, do you think that the installation of a wind farm is a project economically interesting for a territory?

\begin{tabular}{ll}
\hline Completely agree & $23 \%$ \\
Rather agree & $47 \%$ \\
Rather not agree & $15 \%$ \\
Not agree at all & $5 \%$ \\
Do not know & $9 \%$ \\
\hline
\end{tabular}

Table 9. Do you think wind turbines are ... polluting?

\begin{tabular}{ll}
\hline Yes & $11 \%$ \\
No & $83 \%$ \\
Do not know & $6 \%$ \\
\hline
\end{tabular}

Table 10. Do you think wind turbines ... are a threat for migratory birds?

\begin{tabular}{ll}
\hline Yes & $33 \%$ \\
No & $46 \%$ \\
Do not know & $20 \%$ \\
\hline
\end{tabular}

Table 11. Do you think wind turbines damage the landscape?

\begin{tabular}{ll}
\hline Yes & $40 \%$ \\
No & $57 \%$ \\
Do not know & $3 \%$ \\
\hline
\end{tabular}

Table 12. Do you think wind turbines ... are nice?

\begin{tabular}{ll}
\hline Yes & $40 \%$ \\
No & $52 \%$ \\
Do not know & $8 \%$ \\
\hline
\end{tabular}

Table 13. Do you think wind turbines favor local tourism?

\begin{tabular}{ll}
\hline Yes & $10 \%$ \\
No & $79 \%$ \\
Do not know & $11 \%$ \\
\hline
\end{tabular}

Table 14. Do you think wind turbines constitute a risk for the health?

\begin{tabular}{ll}
\hline Yes & $4 \%$ \\
No & $85 \%$ \\
Do not know & $11 \%$ \\
\hline
\end{tabular}

Table 15. Do you think wind turbines can constitute a danger during violent meteorological episodes?

\begin{tabular}{ll}
\hline Yes & $34 \%$ \\
No & $48 \%$ \\
Do not know & $18 \%$ \\
\hline
\end{tabular}

Table 16. Do you think wind turbines are easy to dismantle?

\begin{tabular}{ll}
\hline Yes & $36 \%$ \\
No & $35 \%$ \\
Do not know & $28 \%$ \\
\hline
\end{tabular}

Table 17. Do you think wind turbines have a bad impact on flora and fauna?

\begin{tabular}{ll}
\hline Yes & $19 \%$ \\
No & $50 \%$ \\
Do not know & $31 \%$ \\
\hline
\end{tabular}

Table 18. In a general way, do you consider wind turbines as an opportunity to be encouraged to reduce significantly the part of nuclear power?

\begin{tabular}{ll}
\hline Yes & $61 \%$ \\
No & $25 \%$ \\
Do not know & $13 \%$ \\
\hline
\end{tabular}

\begin{tabular}{lc}
\hline & Table 19. How old are you? \\
\hline-18 & $1 \%$ \\
$18-24$ & $51 \%$ \\
$25-34$ & $17 \%$ \\
$35-49$ & $14 \%$ \\
$50-64$ & $13 \%$ \\
+65 & $4 \%$ \\
\hline
\end{tabular}




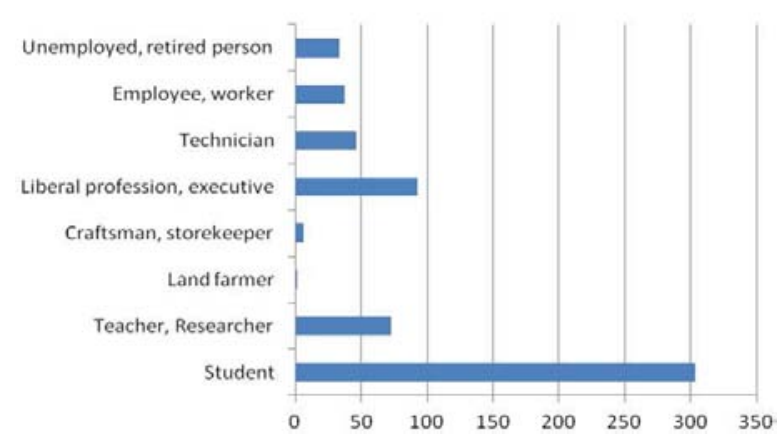

Figure 4. What is your professional activity?

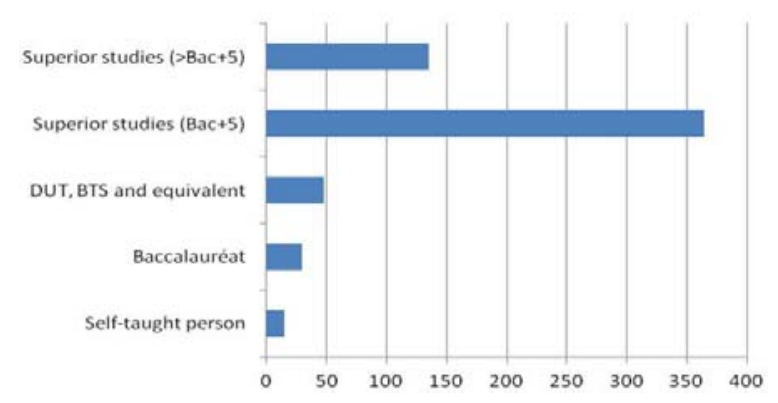

Figure 5. What is your educational background?

\subsection{Raw Results Critical Analysis}

Foundations of social agreement on the development of this RES are confirmed by MEEDDAT (2005) with the same tendencies on the weakness of the risk potential. Then, the population (with a well-educated origin) acts as the general population, finally what corresponds to an important and significant result, considering the number of answers (593). It is not therefore necessary to hire of general analysis of results forward.

Concerning both specific questions, let us note that a great majority considers that the total financial expense linked to this type of energy will be more well brought up than that played nowadays by the purveyor and accepts it (however with only a reasonable additional cost of 10-20\%). It is a notable element in the work which allows probably supporting the promotion of this recent technology of an industrial point of view, as far as reality is not too much beyond this zone of approval.

However, an important element must be signaled, corresponding to the quantity of energy use for a plant in relation to what it can produce during its medium lifetime (about 20 years). The counting performed from data at our disposition mentions an "energy expense" relating in the order of $10 \%$. And, with a cohort, principally scientific (with about $30 \%$ of persons who consider the do not know), the medium value (representing the perception of the investigating) is in the order of 30-35\% for this energy cost. It means that they consider that a third of what is going to produce the Aeolian plant during the medium life will be used for the realization of an Aeolian RES plant. This result points out probably or:

- A general ignorance of subject on behalf of this intellectual world;

- Knowledge more asserted which inserts this type of
RES into the more general context of production of electricity, exploiting thermal power stations with gas to compensate for wind remissions. Then, it is clear that expenses adding up, the medium average is greater than the reality, $10 \%$;

- More simply, from the point of cultural evolution, an agreement on the development of renewable energy with modest energy yield in a sustainable development frame. Would the virtuous formatting undertaken since some decades carry its fruits?

Among the biases of answer in general approached by literature represent in a good place the bias of social desirability and the artefacts of the questions ([33]; [15]). The first results from the will of answering persons show under favorable day ([21]). Second indicates "the error of measure resulting from the adoption of a behavior of specific answer by the people in situation of questioning if he/she believes have detected, even partly, the objective of this questioning" ([33]). In this research, we re-question the existence of these two types slantwise in the light of opportunities introduced by the use of the Internet technologies. Numerous researchers underlined that online studies allowed to economize time and efforts in the collection of quantitative data ([5]; [20]; [18]). Nevertheless, their capacity to reduce the bias of social desirability and the artifacts of the questioning all are not known. Finally, settles the question of the value and the usefulness of uncertainty in speeches and in mass media, with for consequences of the wrong answers to inquiries ([11]). According to Mc Goey ([38]; [39]), uncertainty creates the request of resolutions in the ambiguity which it perpetuates by favoring the debate on the world to be constructed, and in that the culture of the person who answer expresses itself. Techniques are dependent, in varying degrees, them some of the others with between them a certain coherence, what can feel an educated public. Novelty unsettling this interim order "our wish of certainty lead us almost always to sacrifice reality to an abstraction which is translated by postulates" can be then seen in a subjective way in negative, explaining results ([27]).

\subsection{Cross Analysis}

The following figures represent, according to the levels of studies, differentiated from the polling answers to question: "According to you, what is the quantity of energy produced by the Aeolian which will have been used for its realization, its establishment, its maintenance, and dismantling?"

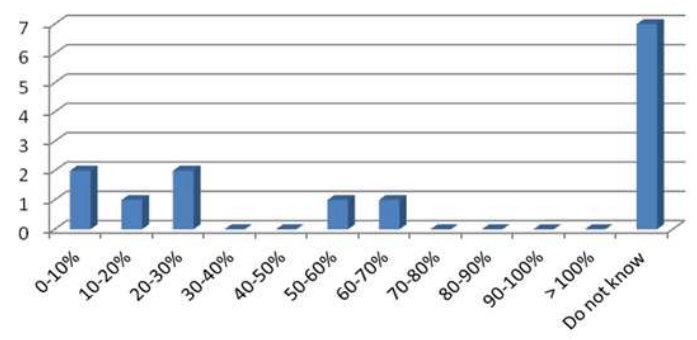

Figure 6. Self-taught people. 


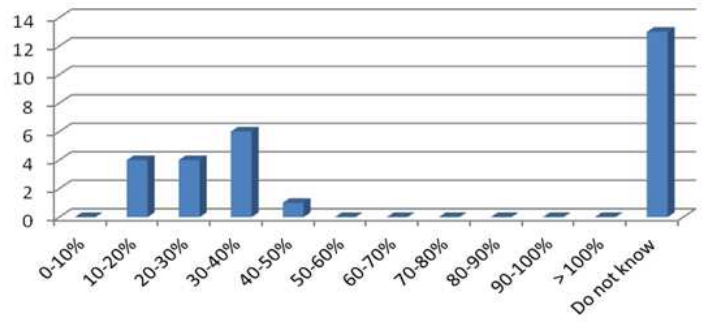

Figure 7. Baccalaureat.

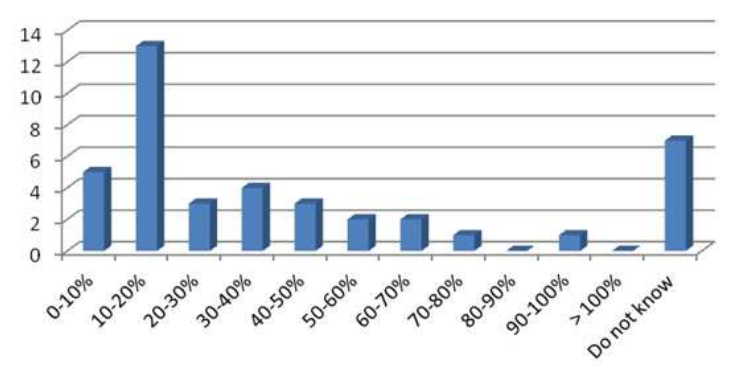

Figure 8. DUT, BTS and equivalent.

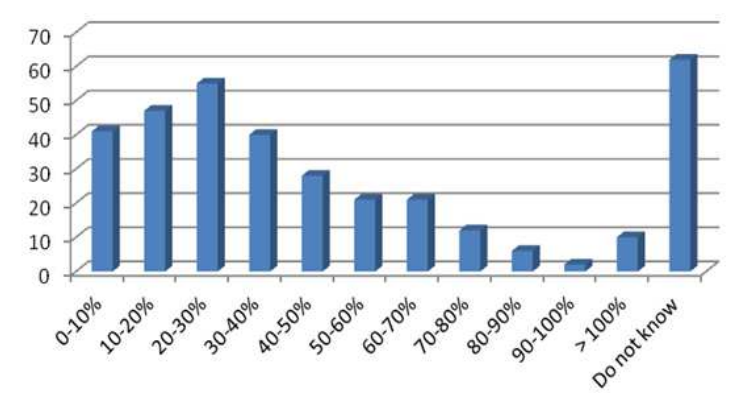

Figure 9. Superior Studies $(<B a c+5)$.

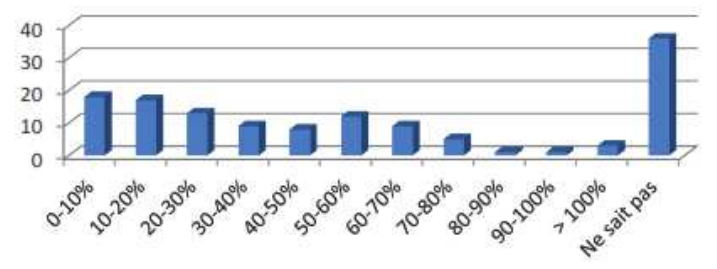

Figure 10. Superior Studies $(>B a c+5)$.

From these data, two types of approaches being led: that corresponding to the measure of the average of the energy cost received by category and that of the report does not "know" about all answers, also by category.

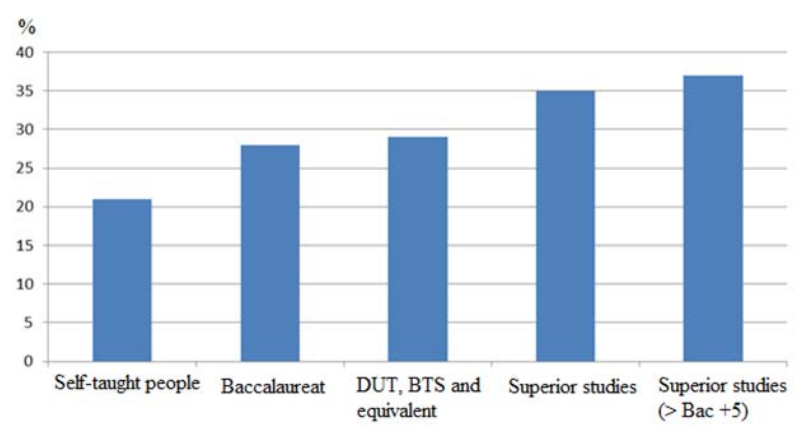

Figure 11. Influence of educational background on perceived average energy cost.

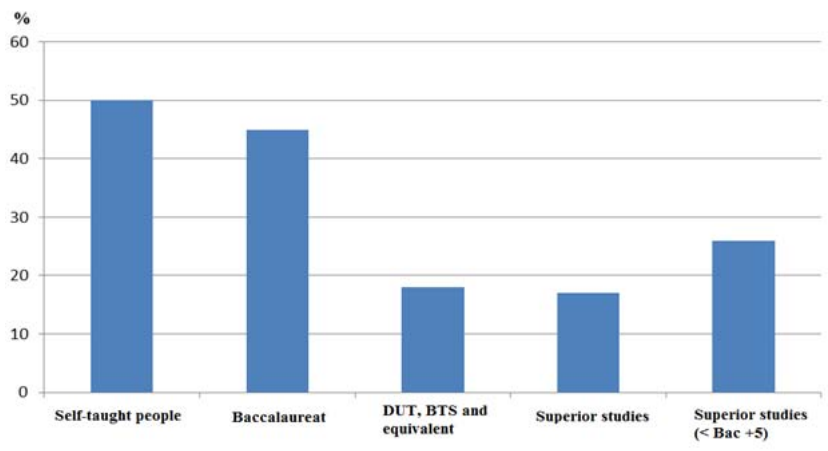

Figure 12. \% Do not know is a function of educational background.

Results introduced on the first figure are completely significant from a statistical point of view (except perhaps for the first category which represents a restricted number of persons having answered the inquiry, that is 14 persons). In facts, the more they have a long training, the more they think that the energy expense of this renewable energy is well brought up. Also, on the following graph, a bigger fairness in answers appears for the first categories which, probably, think to be founded not to know. On the other hand, for the educated, young populations, enthusiasm is of bet, they know or rather they think of knowledge. An important element must be signaled: that of the answer of the university world which answered: $26 \%$ only concerned scientists estimate not know. And, let us remind of it, the object of this inquiry is definitely to search disparate, heterogeneous data to achieve this knowledge (hardly). It serves, in principle, for examining how on a simple example, the correlation between scientific knowledge and public can be developed. In obviousness doubt and rationality were not completely in work in these answers. They could not think that the scientists act, at least in this inquiry, in a less rational way than the general public. The existence of a bias studied by Herbert ([33]) can be at the origin of this result (cf. supra).

\section{General Discussion}

By paraphrasing Badiou ([6]), it is possible to show that the definition of a concept and/or a scientific or technological activity, such as a linked to a complex debate with the public, cannot avoid the production of its effects, the multiplicity of its attributes, so that they can however say alone concept exists or that alone exists the attributes of this last. This remark imposes an analysis of the object linked with its consequences, inside a cross disciplinary expertise. Invisible damage or simply poor choices can turn out to be irremediable of the years later. Anticipation and prevision impose a distribution of risks and desirability between decision-makers, researchers and Society ([10]). In a provocative way, Brune ([14]) writes: 'There is not equivalence between the functional individual and the technocrat of high flight. The first works in the service of second. The one serves the Society of production consumption in the measure of its complete de-politicization; other one manipulates the technocratic ideology to exercise a 
real power, under the alibi of the complexity of management of the modern economy. Functional normality reinforces the function of experts, those who set themselves up as specialists of power to dissuade better the citizen from looking there, from understanding there and from protesting there". It is not that they also reproach the experts, where from temptation to lean on another "suitcase" concept, for the "expert citizen" ([1]). It is definitely on such foundations as responsible research principles were set up.

Example (not initially envisaged) of the questionnaire on RES cannot take a new look at these principles. Nevertheless, connection between science, technology and Society should be probably re-visited to take into account a few considerations:

- It is necessary for the researcher not to merge belief, reliability and proof. It is an important and probably delicate work which goes out of modes of actual research; it is necessary to make the part of things between verifiable elements (what was initially accomplished before throwing the inquiry) and situations (SRR).

- It is important to analyze how stakes of Society, hard beaten by mass media, can lead (or not) in forms of obscurantist manipulations. In this frame, it cannot be "common culture", full of socially correct considerations, shared beliefs which have to impose their law on the scientist.

- The obligation on behalf of the researcher to analyze, if it exists, how an opinion distorts defended by a minority of people (but which are persuaded that it is true) can spread ([28]; [29]).

- The use of the likelihood notion to define the degree of trust of a diagnosis on a scientific and technological plan can lead to not beneficial mistakes.

- The trust in the opinions of the public must be analyzed to light its role of control of researches.

- Scientific committees of validation of plans (except those who grant financings) have to take into consideration: criteria of innovation, social and economic impact, morals, etc. which are recovering from an instant of civilization. Risks of conservative reactions and a weak deepening are to be envisaged.

It is however no way to fasten this essential problem of the research of harmonious relations between those who create and those who use (and who are subjected when risks exist), nor between those who prevent the scientists from searching in this paper. An example which would be to confirm is not enough for a robust conclusion. Nevertheless, it asks the question of how to develop the SRR principles which must again be refined.

\section{Conclusion}

At any case, it is difficult to think that objective knowledge, media "Storytelling", etc. are obvious trumps to change in uniform way collective behaviors of the different components of the Society, even if, in a general way, the whole public is rather favorable to the development of the Aeolian technology as solution, certainly not unique, of RES... The question of a serenely interaction between emerging science knowledge and the public has to be solved... The anticipation, for science and technology, must allow to exceed wait-and-see attitudes and reactions in emergency by assuring analyses of upstream behaviors, to have tools and landmarks to master possible risks, to favor the desired future honestly, what implicates that the possessors of technical knowledge agree to go out of their ivory tower by getting involved in a responsible relationship with the Society.

From the best possible knowledge on the diversity of representations (reduced to the possibility of accepting answers) however does not allow to estimate the possibility of disposing interests of the different actors of a clarification of their role or their interests, with their self-defining facets, to promote diversity and possibility of deepening thinking on particular axes, nor also of searching other partners allowing, as much as possible, to balance debate. In this distribution of ignorance, it would have been possible to make the state of the uncertainties of scientific and technical knowledge, of approximations of knowledge, abuses of interpretation, borders of skills, to measure, at least the spectra of undecided questions and interrogation marks. This desired approach would have been able to allow the catch of distance with ideologies, the too reassuring purposes, oversimplifications... This aspect would therefore be to deepen in another frame.

For the general public, to leave from its perception, to assimilate it with the project to study relations, assumes that the guidelines of plan can be grabbed in themselves, beyond any intense activity of mind, on this side of language ([13]). And, this prior work of ripening for the debate on RES was not indeed hired. It is important to be interested in the way the complexity of systems can be explored; "how weave the links of dependency and interrelationship across which it that make some people, opening new possibilities, possibly developing a network of additional pressures, modelling the skyline on which cast wishes, hopes and fears, determines the concrete frame in which exist the others" ([13]). To learn to value, for citizen, is a means to introduce the notion of honest compromise, the study of the problems of "others ", in brief the return to a collectivization of distribution. Jonas does not say in its approach of "heuristic of anxiety" that it is necessary to cultivate an unselfish, capable fright to disclose hazards of the technology. It is a work to be led in another frame; in any case, for the researcher hired in the development of new technological solutions, it can be difficult to get closer to the Society, especially since, in discreet example (which would require confirmation on other cases), those who are the most capable to think about new topics provide distant elements of answers... Let us try then to invalidate this cogitation of Walter ([48]):" the clairvoyants of misfortunes are scientists today"! 


\section{References}

[1] André J. C., Masse R. (2002) "L'expertise, la science et l'incertitude: l'expertise scientifique ou la langue d'Esope", Environnement, Risques \& Santé, 1, 299-306.

[2] André J. C. (2005) "Complexity and occupational safety and health prevention research" Theoretical Issues in Ergonomic science, 6, 483-507 (2005).

[3] André J. C. (2006) "Weakness of scientific and technical culture of the public and consequences for the development of prevention actions", Theoretical Issues in Ergonomic Science 7, 447-468 (2006).

[4] André J. C. (2013a) “Towards a Socially Responsible Research (SRR) Tableer in Engineering Sciences at CNRS level”, Int. J. Techno-ethics, 4, 39-51.

[5] Aragon Y., Bertrand S., Cabanel M., Le Grand H. (2000) "Enquêtes par Internet: Leçons de quelques expériences" Décisions Marketing, 19, 29-37.

[6] Badiou A. (2009) "Second manifeste pour la philosophie" Champs-Essais/A. Fayard Ed. - Paris (France).

[7] Bayon S, André J. C. (2014) "Towards a responsible research applied to rare earths for a sustainable development" to be published.

[8] Beck U. (2003) "La Société du risque - Sur la voie d'une autre modernité" Flammarion - Champs Ed. - Paris (France).

[9] Bensaude-Vincent B. (2013) "L'opinion publique et la science; à chacun son ignorance" La Découverte Ed. - Paris (France).

[10] Berns T., Blésin L., Jeanmart G. (2010) "Du courage" Ed. des belles lettres - Paris (France)

[11] Best J. (2007) "Why the economy is often the exception to politics as usual" Theory, Culture and Society, 24, 87-109.

[12] Bouleau N. (2013) "L'excessive mathématisation; symptômes et enjeux" 79-1007 in D. Bourg, P. B. Joly, A. Kaufmann (2013) "Du risque à la menace; penser la catastrophe" PUF Ed. - Paris (France).

[13] Breton P., Rieu A. M., Tinland M. (1990) "La techno-science en question" Champ Vallon Ed. - Paris (France).

[14] Brune F. (1985) "Le bonheur conforme" Gallimard Ed. - Paris (France).

[15] Butori R., Parguel B. (2010) "Les biais de réponse - Impact du mode de collecte des données et de l'attractivité de l'enquêteur" http://hal.archivesouvertes.fr/docs/00/63/62/28/PDF/AFM 2010 Version_DA f initive_Raph_28_FA_vrier.pdf.

[16] Cauche J. F. (1999) “A. Giddens et U. Beck: contribution de deux apôtres de la contingence à une sociologie du système pénal" $\mathrm{PhD}$ - Université d'Ottawa - Canada.

[17] Chateauraynaud F., Debaz J., Charriau J. P., Marlowe C. (2013) "Une pragmatique des alertes et des controverses en appui à l'évaluation publique des risques" ANSES/EHESS Ed. - Paris (France)

[18] Cobanoglu C., Warde B., Moreo P. (2001) “A comparison of mail, fax, and Web-based survey methods" International Journal of Market Research, 43, 405-410.

[19] Commissariat général au Développement durable (2009) "L'acceptabilité sociale des éoliennes: des riverains prêts à payer pour conserver leurs éoliennes. Enquête sur quatre sites éoliens françois".

[20] http://www.developpementdurable.gouv.fr/IMG/spipwwwmedad/pdf/B1-08-183AF_document_travail_eoliennes_annexesld_cle01b772.pdf.

[21] Couper M. P. (2000) "Web surveys: A review of issues and approaches" The Public Opinion.

[22] Quarterly, 64, 464-494. Crowne D., Marlowe D. (1960) “A new scale of social desirability independent of Psychopathology", Journal of Consulting Psychology, 24, 349-354. Ellul J. (1998) "Le système technicien" Hachette Ed. - Paris (France).

[23] Euvé F. (2004) "Science, foi, sagesse; peut-on parler de convergence?" Ed. de l'Atelier - Paris (France).

[24] Ewald F. (1998) "L'acceptabilité du risque au seuil du XXIème siècle: de nouveaux modes de régulation s'imposent" Passages, 93, 22-24.

[25] Freitag M. (2002) “L'oubli de la Société; pour une théorie critique à la postmodernité" Presses de l'Université Laval Québec (Canada) and Presses de l'Université de Rennes (France).

[26] Freitag M. (2002) "De la terreur nazie au meilleur des mondes cybernétiques" http://www.dogma.lu/txt/MFTotalitarisme.htm.

[27] Fuster S (Casamayor) (1975) "La tolérance" Gallimard Ed. Paris (France).

[28] Galam S. (2008) "Les scientifiques ont perdu le Nord" Plon Ed. - Paris (France)

[29] Galam S. (2003) "Modelling rumors: the no plane Pentagon French hoax case" Physica A320, 571-580.

[30] Gibbons M., Limoges C., Nowotny H, Schwartmon S., Scott P., Trow M. (1994) "The new production of knowledge: the dynamic of science and research in contemporary societies" Sage Ed. Londres (UK).

[31] Giddens A. (1994) "Les conséquences de la modernité" L'Harmattan Ed. - Paris (France).

[32] Giezendanner F. D. (2012) "Enquêtes: Principaux biais dans la formulation des questions" http://icp.ge.ch/sem/cmsspip/spip.php?article1765.

[33] Herbert M. (2007) “Que se passe-t-il lorsque les répondants à un questionnaire tentent de deviner l'objectif de recherche ? Le biais du répondant: conceptualisation, mesure et étude d'impact" Actes du Congrès de l'AFM, Aix-les-Bains (France).

[34] Institut de sondages Louis Harris (2005) "Opinion des Français sur l'énergie éolienne". http://www.resregions.info/fileadmin/res_e_regions/_nergie_olienne_01.pdf.

[35] IPSOS Public Affairs (2010) "Perception de l'énergie éolienne en Wallonie" http://edora.org/doc/news_32/Ipsos_Resume_\%20Executif.pd f. 
[36] Lascoumes P., Le Bourhis P. (1998) "Le bien commun comme construit territorial. Identités d'action et procédures" Politix 42, 37-66.

[37] Lenoir F. (2012) "La guérison du monde" Fayard Ed. - Paris (France).

[38] Mc Goey L. (2009) "Pharmaceutical controversies and the performance value of uncertainty" Science as Culture 18, 151164.

[39] Mc Goey L. (2012) "Strategic unknowns: towards sociology of ignorance" Economy and Society 41, 1-16.

[40] Miraton D. (2013) "Culture de l'innovation et éducation; retour d'expérience d'industriel" 237-250 in M. F. ChevallierGuyader, M. Girel Ed. "Partager la Science; l'illettrisme scientifique en question" Actes Sud Ed. - Paris (France).

[41] Moniteur. fr (2014-05-14) "Les français favorables à la transition énergétique" http://www.lemoniteur.fr/137energie/article/actualite/24401448-les-francais-favorables-ala-transition-energetique.

[42] Nowotny H. (2005) "Interdisciplinarity research - why does it matter?" NEST conference

$\mathrm{http}: / /$ www.nestconference.com/pdf/nowotny.pdf.

[43] Nowotny H., Scott P., Gibbons M. (2003) "Repenser la Science" Belin Ed. - Paris (France).

[44] Pesqueux Y. (2013) "Le management de l'innovation dans les modèles de gouvernance de l'entreprise" 129-141 in Boutiller S., Djellal F., Uzinidis D. Eds. "L'innovation: analyser, anticiper, agir" P. Lang Ed. - Bruxelles (Belgium).

[45] Redlingshöfer B., Métais A., André J. C. (2014) “Complexité, risques incertains, précaution et débat public" Environnement, risques et santé, 13, 222-231.

[46] Sclove R. (2003) "Choix technologiques, choix de Société" Ed. Charles Jacob Léopold-Mayer, Descartes et Cie - Paris (France).

[47] Stengers I. (2013) "Une autre science est possible: manifeste pour un ralentissement des sciences" Les empêcheurs de penser en rond Ed. - Paris (France).

[48] Walter F. (2008) "Catastrophes; une histoire culturelle XVIXXIème siècle" Seuil Ed. - Paris (France). 